\title{
Objective and subjective analysis of women's voice with idiopathic Parkinson's disease
}

\author{
Análise objetiva e subjetiva da voz de mulheres portadoras da doença de \\ Parkinson idiopática
}

Riviana Rodrigues das Graças', Ana Cristina Côrtes Gama², Francisco Eduardo Costa Cardoso³, Bárbara Pereira Lopes' ${ }^{1}$ lara Barreto Bassi

\begin{abstract}
Objective: To compare the voice quality of women with idiopathic Parkinson's disease and those without it. Methods: An evaluation was performed including 19 female patients diagnosed with idiopathic Parkinson's disease, with an average age of 66 years, and 27 women with an average of 67 years-old in the Control Group. The assessment was performed by computed acoustic analysis and perceptual evaluation. Results: Parkinson's disease patients presented moderate rough and unstable voice quality. The parameters of grade, roughness, and instability had higher scores in Parkinson's disease patients with statistically significant differences. Acoustic measures of Jitter and period perturbation quotient (PPQ) significantly differ between groups. Conclusions: Parkinson's disease female individuals showed more vocal alterations compared to the Control Group, when both perceptual and acoustic evaluations were analyzed.
\end{abstract}

Key words: speech acoustics, Parkinson's disease, voice.

\section{RESUMO}

Objetivo: Comparar a qualidade vocal de portadoras da doença de Parkinson idiopática com mulheres sem a doença. Métodos: Foram avaliadas 19 pacientes do sexo feminino, com diagnóstico de doença de Parkinson idiopática e média de idade de 66 anos, e 27 mulheres com média de idade de 67 anos pertencentes ao Grupo Controle. A avaliação foi realizada por meio de análise acústica computadorizada e análise perceptivo-auditiva da voz. Resultados: As portadoras da doença de Parkinson apresentaram qualidade vocal rouca de grau moderado e instável. Os parâmetros de grau do desvio vocal, rugosidade e instabilidade apresentaram maiores valores no grupo com doença de Parkinson, sendo que houve diferença estatisticamente significante. Medidas acústicas de Jitter e quociente de período de perturbação (PPQ) apresentaram diferença estatisticamente significativa entre os grupos. Conclusões: Quando comparadas ao Grupo Controle, as mulheres portadoras da doença de Parkinson apresentaram maiores alterações vocais ao serem estudadas por meio de análise acústica e perceptivo-auditiva.

Palavras-Chave: acústica da fala, doença de Parkinson, voz.

Parkinson's disease (PD) is a syndrome occasioned by the death of neurons in the substantia nigra, leading to a reduction in the production of dopamine, which is a neurotransmitter synthesized in this brain region ${ }^{1,2}$. As a result, there is the occurrence of akinesia, postural change, rest tremor, and muscular rigidity. It can also be seen depression, sleep disturbance, cognitive and autonomic disorders as a non-motor symptoms ${ }^{3}$.

Studies have demonstrated that speech and voice disorders may also characterize the context of patients, manifesting in about $75 \%$ of them ${ }^{4}$.
The signals in the speech and voice are associated directly with akinesia intensity and are related with a breathy and hoarse voice with or without tremor, besides an articulatory incoordination and reduction of prosody and intensity ${ }^{5,6}$.

This commitment to communication of Parkinson's patients can cause them to reduce the potential for interaction with other individuals and, in severe cases, can reach social isolation ${ }^{1}$.

Given the personal and social impacts caused by the development of $\mathrm{PD}$, it becomes of paramount importance to

\footnotetext{
Universidade Federal de Minas Gerais, Medicine College, Department of Speech and Language Therapy, Belo Horizonte MG, Brazil.

${ }^{1}$ Graduation Student in Speech and Language Therapy;

${ }^{2}$ Teacher of the Department of Speech and Language Therapy;

${ }^{3}$ Teacher of the Department of Medical Clinical;

4Speech Therapist - PhD in progress in Epidemiology.

Correspondence: Riviana Rodrigues das Graças; Universidade Federal de Minas Gerais; Avenida Alfredo Balena 190 / Sala 251; 30130 -100

Belo Horizonte MG - Brasil; E-mail: rivianarg@yahoo.com.br

Support: FAPEMIG.

Conflict of interest: There is no conflict of interest to declare.

Received 29 September 2012; Received in final form 28 February 2012; Accepted 06 March 2012
} 
recognize the vocal profile of these individuals in order to enable an effective speech and language therapy intervention, ensuring a better quality of life.

This research aims at comparing the voice quality of women with idiopathic PD and those that belong to the Control Group without the illness, by means of the acoustic analysis and perceptual evaluation.

\section{METHODS}

It is a cross-sectional case-control study with a convenience sample, in which voices of women with and without PD were evaluated by computed acoustic analysis and perceptual evaluation.

Subjects with PD were recruited at the Movement Disorders Clinic, Neurology Service of Bias Fortes Hospital das Clínicas of Minas Gerais Federal University (HC/UFMG), before or after the medical appointment. It was obtained an evaluation group of 19 female patients diagnosed with idiopathic PD, aged 62 to 74 years, with a mean of 66 years-old. The inclusion criteria for participation in the PD Group were: female patients diagnosed with idiopathic PD, according to the Brain Bank of the UK PD Society Brain Bank Clinical Diagnostic Criteria at the stages 1 to 3 of the Hoehn-Yahr scale of disability.

The Control Group was composed of 27 individuals with ages ranging from 60 to 80 years-old with a mean age of 67 , without history of neurological disease and disorder of communication. The participants in this group were companions of patients of Hospital das Clínicas at UFMG.

The exclusion criteria for this study were: history of laryngeal and voice disorders, diagnosis of associated neurological disorders, not understanding the requested task, and having had conducted voice therapy.

The study group was limited to females, since the variable gender affects the results of acoustic measurements analyzed in this study ${ }^{7}$.

It was found in a previous study performed by the same research group with patients of the same treatment center, where there was no statistically significant difference between the acoustic parameters of fundamental frequency, jitter, shimmer, voice turbulence index (VTI) and harmonic-to-noise ratio (HNR) between the groups with PD in stages "off", "on" and the Control Group. With these results and considering the uncomfortable position of keeping the people on stage "off" the drug, in this study all participants were in stage "on" of medication".

The decision of not separating into groups with different stages of the disease was based on the result of a study with 50 patients. The study showed that phonation (fundamental frequency, vocal quality, and intensity) presented with similar values in all stages of PD and was not associated with the disease duration ${ }^{9}$.
All patients underwent voice and speech recording by sustained vowel /a/ and connected speech (counting 1 to 20 and days of the week).

The speech and language evaluations came on the same day of the consultation with the neurologist. All patients were duly informed about their participation in the research, and allowed the use of their voices after signing the informed consent, according to Resolution 196/96.

To perform the acoustic analysis, the voices were recorded with the patients in a soundproof booth, using a headset microphone $\mathrm{AKG}^{\circledR}$. It was used a Dell ${ }^{\circledR}$ computer, model Optiplex GX260, with Direct Sound ${ }^{\circledR}$ professional sound board. The acoustic analysis software used was the CSL, Kay Elemetrics ${ }^{\circledR}$.

For the perceptual analysis, the number of evaluators and voices of the sample was obtained from the index Kappa proposed by Fleiss, with a statistical power of $80 \%$ and a significance level of $5 \%$. In order to determinate the intrarater reliability, $20 \%$ of the voices were repeated randomly, totalizing 55 issues. Three speech therapists with experience in voice participated of the study, and the professionals who had intrarater over $70 \%$, as measured by Kappa statistics, had the responses of the perceptual analysis selected.

The perceptual evaluation of the recorded voices was performed with headphones Bose ${ }^{\circledR}$ for both speech materials: sustained vowel and connected. It was used the GBRASI scale for the perceptual analysis ${ }^{10}$, considering $\mathrm{G}$ as the grade of the dysphonia, $\mathrm{R}$ as roughness, $\mathrm{B}$ as breathiness, $\mathrm{A}$ as asthenia, $\mathrm{S}$ as strains, and I as instability. At this scale, the evaluator must indicate the degree of change for each parameter assessed, which ranges from 0 to 3 . Grade 0 is considered for no alteration, 1 for mild, 2 for moderate, and 3 for severe.

The acoustic parameters used from the options of acoustic analysis were: fundamental frequency in Hertz, Jitter in percentage, period perturbation quotient in percentage (PPQ), shimmer in percentage, amplitude perturbation quotient in percentage (APQ), HNR.

The value of the fundamental frequency used was the average of all periods of the frequency extracted and the value of normality indicated by the guide's program, which is $243.973 \mathrm{~Hz}$.

The parameters that measure the frequency's perturbation in the short-term chosen were Jitter expressed as a percentage, which is an index of fundamental frequency variability, and PPQ expressed as a percentage, which is the relative average of frequency disturbance from five to five periods (average of five points). The normal ranges indicated by the program to such acoustic parameters are 0.633 and $0.366 \%$, respectively.

The parameters that measure the perturbation of amplitude in the short-term chosen were: shimmer expressed as a percentage, which is an index of variability of the sound wave amplitude, and APQ expressed as a percentage, which is the relative average of sound wave amplitude variability from 11 
to 11 periods (average of 11 points). The normal ranges indicated by the program to such acoustic parameters are 1.76 and $1.397 \%$, respectively.

The noise measures used were HNR, which relates the harmonic and noise component of the acoustic wave with normal range indicated by the program as $0.112 \mathrm{~dB}$.

The statistical analysis of perceptual data was performed using the Statistical Package for the Social Sciences (SPSS), version 17.0. Firstly, it was carried out a descriptive analysis with measurements of percentage. Later, to verify the difference in voice quality between the group of patients with PD and the Control Group, the average of GRBASI parameters for each group was calculated. The difference between the averages was calculated using the nonparametric test for becoming independent samples, Mann-Whitney. The significance level was $95 \%$.

This research was approved by the Research Ethics Committee of the Federal University of Minas Gerais, on the report number 676/07.

\section{RESULTS}

In the perceptual evaluation of sustained vowel (Table 1) and connected speech (Table 2), the parameters grade $(\mathrm{G})$, roughness (R), and instability (I) showed higher values in the PD Group with a statistically significant difference.

In the acoustic analysis, the parameters jitter and PPQ presented statistically significant differences between their means with higher value in the PD Group compared to the one without PD (Table 3).

\section{DISCUSSION}

All voice changes in patients diagnosed with $\mathrm{PD}^{3}$ and their consequences for communication and quality of life were recognized. This study aimed at comparing the voice quality between patients with idiopathic PD and women without the disease. It was observed that in both analyses, perceptual and acoustic, the group of women with PD presented a worse voice quality. The difference between the groups was statistically significant for grade, roughness, instability, jitter, and PPQ.

As to the grade, the literature agrees that the voice of patients with PD is more altered than the one of older women ${ }^{11-13}$, although studies show that the voice of the elderly often presents mild to moderate changes in the parameter grade ${ }^{14}$, and it was possible to verify that women with PD had more significant changes in this parameter.

As to the roughness parameter, studies indicate that the voice of individuals with PD is rougher when compared with controls unchanged, which agrees with this study ${ }^{11}$. The irregularity
Table 1. Mean and standard deviation of GRBASI scale parameters for the perceptual analysis of the sustained vowel /a/, comparison between cases and controls.

\begin{tabular}{ccccc} 
& Group & Mean & Standard deviation & p-value \\
\hline G & Case & 2.03 & 0.88 & 0.027 \\
& Control & 1.60 & 0.76 & \\
R & Case & 1.58 & 0.82 & 0.043 \\
& Control & 1.19 & 0.79 & \\
B & Case & 1.11 & 0.83 & 0.271 \\
& Control & 0.90 & 0.66 & \\
A & Case & 0.21 & 0.47 & 0.298 \\
& Control & 0.13 & 0.39 & \\
S & Case & 0.92 & 0.88 & 0.518 \\
& Control & 1.06 & 0.97 & \\
I & Case & 1.66 & 1.04 & 0.025 \\
& Control & 1.17 & 0.9 & \\
\hline
\end{tabular}

Mann-Whitney U Test

G: grade; R: roughness; B: breathiness; A: asthenia; S: strain; I: instability.

Table 2. Mean and standard deviation of GRBASI scale parameters for the perceptual evaluation of connected speech, comparison between cases and controls.

\begin{tabular}{ccccc} 
& Group & Mean & Standard deviation & p-value \\
\hline G & Case & 1.26 & 0.92 & 0.016 \\
& Control & 0.81 & 0.70 & \\
R & Case & 1.21 & 0.91 & 0.013 \\
& Control & 0.75 & 0.67 & \\
B & Case & 0.68 & 0.70 & 0.122 \\
& Control & 0.44 & 0.50 & \\
A & Case & 0.18 & 0.45 & 0.273 \\
& Control & 0.08 & 0.27 & \\
S & Case & 0.32 & 0.57 & 0.918 \\
& Control & 0.31 & 0.58 & \\
I & Case & 0.71 & 0.83 & 0.001 \\
& Control & 0.21 & 0.50 & \\
\hline
\end{tabular}

Mann-Whitney U Test

G: overall grade; R: roughness; B: breathiness; A: asthenia; S: strain; I: instability.

Table 3. Mean and standard deviation of acoustic analysis parameters, comparison between cases and controls.

\begin{tabular}{lcccc} 
& Group & Mean & Standard deviation & p-value \\
\hline Jitter & Control & 1.05 & 1.06 & 0.045 \\
\multirow{4}{*}{ Shimmer } & Case & 2.18 & 2.38 & \\
& Control & 4.40 & 3.06 & 0.953 \\
HNR & Case & 5.52 & 5.14 & \\
& Control & 0.16 & 0.10 & 0.090 \\
PPQ & Case & 0.27 & 0.31 & \\
& Control & 0.64 & 0.78 & 0.048 \\
APQ & Case & 1.33 & 1.66 & \\
& Control & 3.18 & 2.44 & 0.281 \\
F0 & Case & 4.82 & 4.43 & \\
& Control & 213 & 43.53 & 0.197 \\
& Case & 198 & 42.85 &
\end{tabular}

Mann-Whitney $\cup$ Test

FO: fundamental frequency; Jitter: index of fundamental frequency variability in the short-term; Shimmer: index of variability of the sound wave amplitude; NHR: harmonic-to-noise ratio; PPQ: period perturbation quotient; APQ: amplitude perturbation quotient. 
of vocal fold vibration in PD can be explained by the rigidity and hypokinesia of the muscles involved in the speech ${ }^{11}$.

In relation to the instability, it is known that the voice of individuals with PD is more altered ${ }^{11-13,15}$. In a study that correlated the perceptual evaluation and the contractile pattern of intrinsic muscles of the larynx, it was found vocal tremor, leading to instability. Nevertheless, the presence of tremor was not correlated with the pattern of muscles ${ }^{12}$.

Although literature shows a statistically significant difference in such parameters, breathiness ${ }^{11,13}$, asthenia ${ }^{11,16}$, and strain $^{13}$, the same was not found in this study. This difference may be related to the scale used and the sample size.

In relation to data from the acoustic analysis, it was verified that women with PD (Table 3) presented statistically significant changes in frequency perturbation measures (Jitter and PPQ) compared to the Control Group. Individuals with PD have a contractile pattern of the intrinsic muscles of the larynx with the presence of involuntary motor activity, even on vocal rest, as indicated in some studies, which may be related to the difficulty in controlling the vibration of vocal folds ${ }^{12,17}$.

A study that conducted an acoustic analysis of individuals with PD after undergoing surgery for posteroventral pallidotomy showed that even after surgery, jitter and PPQ value remained high. This study indicated that surgical treatment has little interference in the voice of individuals with $\mathrm{PD}^{8}$. Studies have found similar results concerning the increase of acoustic measures related to the frequency disturbance, which confirms the results of this study ${ }^{7,18,19}$. PD male subjects treated with dopaminergic drugs have higher fundamental frequency (Fo) values when compared to the Control Group, due to the rigidity and hypokinesia ${ }^{13,16}$.
Another study carried out in order to perform an acoustic analysis of the voices of women with PD compared with normal controls has found that the Fo of middle-aged women with PD was at the range of male and the Fo of the controls at the lower range of female. The process of aging and its consequences seems to act as a factor that interferes in acoustic voice change, but apparently the PD and age of onset can accentuate these changes, impacting negatively on the $\mathrm{Fo}^{4,14}$. In spite of have taken a lower Fo in the PD Group, in this study there was no statistically significant difference in such measure. These results can be explained by sample size and stage of disease. Future studies that control the stage of the disease can explore this aspect.

The values of acoustic measures of intensity aperiodicity (shimmer and APQ) showed no significant differences between the two groups, which is similar to the results in the literature ${ }^{19}$.

NHR measures showed no significant differences between groups, which disagree with the literature ${ }^{19}$. This difference may be related to the number of subjects in this study and the acoustic analysis program used.

In conclusion, patients with PD treated at the Movement Disorders Clinic of the HC-UFMG present moderate rough and unstable voice quality in the tasks of sustained vowel and connected speech. The acoustic measures of frequency aperiodicity (jitter and PPQ) are also altered in this group.

Female individuals with PD have higher vocal changes compared to the Control Group, when voice is both perceptual and acoustic analysed, which shows the importance of speech and language therapy in this group, enabling a better communication of these individuals.

\section{References}

1. Lana RC, Álvares LMRS, Nasciutti-Prudente C, Goulart FRP, TeixeiraSalmela LF, Cardoso FE. Percepção da qualidade de vida de indivíduos com doença de Parkinson através do PDQ-39. Rev Bras Fisioter 2007;11:397-402.

2. Bigal A, Harumi D, Luz M, De Luccia G, Bilton T. Disfagia do Idoso: estudo videofluoroscópico de idosos com e sem doença de Parkinson. Distúrb Comum 2007;19:213-223.

3. Azevedo LL, Cardoso F. Ação da levodopa e sua influência na voz e na fala de indivíduos com doença de Parkinson. Rev Soc Bras Fonoaudiol 2009;14:136-141.

4. Ferreira FV, Cielo CA, Trevisan ME. Medidas vocais acústicas na doença de Parkinson: estudo de casos. Rev CEFAC 2010;12:889-898.

5. Steidl SEM, Ziegler JR, Ferreira FN. Parkinson's disease: literature revision. Disc Scientia 2007;8:115-129.

6. Sabine S, Wenke V, Schlegel U. Vowel articulation in Parkinson's disease.J Voice 2011;25:467-472.

7. Carrillo L, Ortiz KZ. Análise vocal (auditiva e acústica) nas disartrias. Pro-Fono Rev Atual Cient 2007;19:381-386.

8. Santos LL, Reis LO, Bassi I, Guzella C, Cardoso F, Reis C, et al. Acoustic and hearing-perceptual voice analysis in individuals with idiopathic Parkinson's disease in "on" and "off" stages. Arq Neuropsiquiatr 2010;68:706-711.
9. Dias AS. Características fonoarticulatórias na doença de Parkinson de início na meia idade e tardio [tese]. Faculdade de Medicina da Universidade de São Paulo, São Paulo; 2006.

10. Hirano M. Clinical examination of voice. New York: Springer Verlag; 1981:81-84

11. Gasparini G, Diaféria G, Behlau M. Queixa vocal e análise perceptivoauditiva de pacientes com doença de Parkinson. R Ci Med Biol 2003;2:72-76.

12. Zarzur AN, Duarte IS, Gonçalves GNH, Martins MAUR. Eletromiografia laríngea e análise vocal em pacientes com mal de Parkinson: estudo comparative. Braz J Otorhinolaryngol 2010;76: 40-43.

13. Silva LF. Comparação da avaliação perceptivo-auditiva, acústica vocal e protocolo de qualidade de vida em voz de indivíduos com e sem doença de Parkinson Idiopática [monografia]. Faculdade de Medicina Universidade Federal de Minas Gerais, Belo Horizonte; 2010.

14. Gama ACC, Alves CFT, Cerceau JSB, Teixeira LC. Correlação entre dados perceptivo-auditivos e qualidade de vida em voz de idosas. Pro-Fono Rev Atual Cientif 2009;21:125-130.

15. Skodda S, Visser W, Schlegel U. Gender-related patterns of dysprosody in Parkinson's disease and correlation between speech variables and motor symptoms. J Voice 2009;25:76-82. 
16. Zarzur AN, Duprat CA, Shinzato G, Eckley CA. Laryngeal electromyography in adults with Parkinson's disease and voice complaints. Laryngoscope 2007;117:831-834.

17. Mourão LF, Aguiar PMC, Ferraz FAP, Behlau MS, Ferraz HB. Acoustic voice assesment in Parkinson's disease patients submitted to posteroventral pallidotomy. Arq Neuropsiquiatr 2005;63:20-25.
18. Gamboa J, Jiménez-Jiménez FJ, Nieto A, Montojo J, Ortí-Pareja M, Molina JA, et al. Acoustic voice analysis in patients with Parkinson's disease treated with dopaminergic drugs. J Voice 1997;11:314-320.

19. Douglas A. Rahn III, Chou M, Jiang JJ, Zhang Y. Phonatory Impairment in Parkinson's disease: evidence from nonlinear dynamic analysis and perturbation analysis. J Voice 2007;21:64-71. 